En El sollozo del hombre blanco se reconoce en el tercermundismo un síntoma de la esterilidad intelectual de la izquierda, que debe buscar fuera de sus fronteras pueblos a quienes liberar, pues la lucha de clases y la revolución marxista tienen cada vez menos importancia en casa. En palabras del Dr. Wahl del Institute of French Studies de la Universidad de Nueva York, el surgimiento del tercermundismo representa para la izquierda "el abandono del proyecto revolucionario".

Pero El sollozo del hombre blanco no es una sistemática invalidación de los ideales contemporáneos; es una invitación a hacer una re-lectura del pasado reciente y entender el comportamiento de toda una generación a través de la sucesión de modas intelectuales. Propone la actualización del concepto de un Tercer mundo que quizás nunca existió y, lo más importante, propone una manera alternativa de ayudar a los países en desarrollo viéndolos como son, en lugar de sentimentalizarlos. Es una alternativa para los que buscamos definir un curso entre la apatía y la autohumillación en nuestras relaciones con la humanidad.

\title{
DANIEL PASTOR
}

Eduardo Montes, La URSS de Gorbachov (más socialismo, más democracia), Ediciones de Cultura Popular, México, 1987, 143 pp.

El subtítulo señala bien las intenciones del autor del libro; en efecto se trata de un ferviente alegato en favor de la renovación iniciada en abril de 1985 por el equipo de Gorbachov. El autor lo manifiesta tantas veces a lo largo del texto como si hubiera querido exorcisar cualquier sospecha de que los cambios promovidos en la URSS bajo el secretariado de Gorbachov representan una desviación de la línea socialista. La primera pregunta que surge durante la lectura del libro: ¿Por qué tanta insistencia en este punto? ¿No sería más conveniente que el propio lector formulara su criterio al respecto? Ciertamente no es sólo la cuestión del - estilo, de la estructuración del libro derivadas del apresuramiento en la redacción del texto, como lo confiesa el autor en el prólogo. Me parece que más bien así se plasma la plena identificación del autor con el programa de reformas actuales en la URSS en cuanto a su orientación y su amplitud. E. Montes, dirigente del PSUM a la sazón de escribir el texto, se sintió profundamente impresionado durante sus tres estadías en la URSS, entre octubre de 1985 y junio de 1986, por las conversaciones sostenidas con numerosos 
activistas soviéticos, algunos de ellos en puestos claves dentro del stablishment (las más importantes reproducidas en la segunda parte del libro). El texto es pues el fruto de sus observaciones y, sobre todo, de las entrevistas con personalidades soviéticas y mexicanas, aunque el autor no los menciona por sus nombres. El autor califica así al actual programa de reestructuración del sistema:

"La reconstrucción lo abarca todo, no únicamente la economía; incluye la política, la cultura, medio en que se realizan importantes transformaciones como son los ensayos de autogestión en el teatro y el cine; comprende también la educación, el papel del partido gobernante, sus relaciones con el Estado, las organizaciones sociales y la función de éstas. Impulso especial se da a la transparencia informativa (glasnost), lo que se evidencia en el cambio radical que está sufriendo la prensa central y la televisión". (p. 13)

Montes no esconde sus simpatías por la perestroika (reestructuración, reconstrucción). Más aún, no escatima palabras de elogio, las que por su altisonancia ya no corresponden al nuevo espíritu del tiempo, para utilizar el término de Hegel; por ejemplo, al hablar de Mijaíl Gorbachov no hesita calificarlo "impulsor entusiasta y combativo de las reformas" (p. 13). Tampoco parece concordar la declaratoria, conocida y abusada en decenios pasados, con las exigencias del momento que es el romper con la inercia y el burocratismo - que el autor enfatiza- cuando afirma:

“de esto al parecer están convencidos el Buró Político y todos los dirigentes del PCUS, propagandistas e impulsores de los cambios en todos los niveles cie la dirección política y económica; precisan una enérgica actividad política e ideológica, con amplio respaldo de las masas" (p. 73).

Seguramente, el autor no se percata de que aquí radica una contradicción interna del enunciado: si todo el mundo está en pro del programa de reformas, ¿por qué entonces tanta resistencia y oposición a él?, oposición que Montes menciona en múltiples ocasiones al referirse a los intentos reformistas en el pasado, asi como al actual programa de reformas. Este recurso retórico (de que todo el mundo, todos los dirigentes...) debe pertenecer tam- 
biẻn al pasado, ya sea sólo por su inconsistencia de lógica elemental.

Quiero precisar que de ninguna manera pretendo invalidar el libro por la identificación del autor con el programa de renovación del sistema soviético bajo la dirección de Gorbachov. Por el contrario, hago patente el reconocimiento al autor por ser el primero en escribir un libro que aborda de manera global la era de Gorbachov, tan prometedora en todos los sentidos. Coincido plenamente con el autor en que el actual programa abarca todas las esferas de la vida. El tema es de suma importancia que amerita amplias discusiones y, sobre todo, estar muy atento de lo que está pasando en aquel país. Mi propósito es polemizar con el autor, demostrar algunas incongruencias suyas, ciertas omisiones y algunos errores, sin menospreciar el valor del texto.

Así, cabe destacar que el autor deja deliberadamente confuso el meollo de la cuestión cuando confunde dos niveles: el del anuncio del vasto programa de reformas que se propuso la dirección soviética con su realización, con su consumación. Por un lado Montes sostiene:

Al iniciarse 1987 la reforma económica radical en la URSS entra a una fase decisiva. Todas las empresas industriales empiezan a trabajar conforme a un nuevo método: la autogestión económica completa. [...] Se pone en manos de las direcciones de las empresas y los colectivos laborales de las mismas, cuya autonomía e iniciativa aumentan drásticamente, la responsabilidad de garantizar el funcionamiento, eficacia y rentabilidad de las empresas" (p. 12).

Por otro lado, el autor no pasa por alto advertencias de sus interlocutorer soviéticos de que la realización de este programa de perestroika será una tarea ardua que requerirá mucho esfuerzo y, por supuesto, está lejos de verse coronada con éxito. Añadamos que la prensa diaria reporta regularmente las amonestaciones de altos dirigentes soviéticos en el sentido de que los cambios deseados son demasiado lentos, de que están bloqueados por la burocracia, incluyendo la del Comité Central del PCUS, del gobierno federativo y de las repúblicas. No obstante hay que reconocer que ya fueron introducidos en la práctica ciertos mecanismos nuevos a título de experimentos respecto a una mayor autonomía administrativa, financiera, laboral, de intercambios dentro y fuera de las fronteras nacionales. Igualmente, fueron emprendidas importantes modificaciones en la estructura administrativa de la economía al fusionar algunos ministerios por ramas y en el 
funcionamiento de la central de planificación(Gosplan), simplificando y descentralizando las decisiones, lo que ha permitido concentrarse sobre cuestiones estratégicas de la economía otorgando una mayor iniciativa a las direcciones gerenciales de las fábricas. Pero aún falta una plena reestructuración del conjunto de la economía; más aún, no existe todavía elaborado un programa completo de la reforma económica, como lo admiten los propios responsables soviéticos e investigadores serios extranjeros a quienes nadie podría acusar de "antisovietismo", como lo es $\mathbf{M}$. Lavigne de París-Sorbona. Las fuentes soviéticas anuncian que se está trabajando a ritmo acelerado para elaborar un paquete legislativo orientado a sentar las bases legales nuevas para el funcionamiento del conjunto de la economía.

Otro problema nodal que se desprende del análisis del autor y que queda abierto es el siguiente: ¿de qué o de quién depende que ciertas críticas del funcionamiento del modelo soviético están reconocidas como justas o, por el contrario, están consideradas como actividades antisoviéticas y, por consiguiente, perseguidas con todo el rigor de la ley o la arbitrariedad absoluta? ¿No es acaso acertada la hipótesis de que tantos pronunciamientos oficiales en la actualidad hubieran sido recibidos como denigrantes, falsas imágenes de la realidad soviética y sus autores condenados a purgar largos años de gulag? Creemos no equivocarnos en sostener que las propias palabras de Montes escritas hace un par de años no hubieran sido vistas como "crítica constructiva" $o$, tal vez, el autor no se hubiera atrevido a pronunciarlas por su calidad de dirigente del PSUM, por ejemplo:

"el inmovilismo casi completo fue característica de la economía, la política y la cultura soviéticas: se mantuvo el modelo de dirección extremadamente centralizada que redujo a la nada, o casi, las posibilidades de participación de las masas en las decisiones y adormeció su iniciativa. El mecanismo de gestión económica y política creó su propia estabilidad y generó grupos de interés; dominaron concepciones burocráticas y se desarrolló cierta corrupción a la sombra de una economía paralela; plasmó también una forma de vida" ( $p$. 12).

La respuesta a este interrogante parece ser única: porque esta vez provienen de arriba, es decir, que gozan de una aceptabilidad oficial y corresponden al programa de la dirección del partido, y mientras que anteriormente fueron planteadas por las personas 
fuera del establishment, estigmatizados y perseguidos por la llamada disidencia. Un paso siguiente en nuestro razonamiento: ¿aceptaría el autor la tesis de que la llamada disidencia ha sido en su mayoría la obra de la esclerosis del sistema que perseguía cualquier crítica, por más justificada que fuese? Si comparamos las críticas de los marxistas democráticos, al estilo de los hermanos Medvedev, o los llamados socialistas independientes, tipo B. Weil, Plisch, no encontramos diferencias de fondo con los planteamientos oficiales de hoy en día. El autor no se pronuncia al respecto y sus escasas referencias a la disidencia tienen el tono claramente negativo. Observemos, por nuestra parte, que también respecto al funcionamiento de los órganos de represión, principalmente la famosa KGB, la procuraduría, los tribunales, la milicia, se externan fuertes críticas por actuar de manera precipitada, violatoria de las normas elementales de defensa, basándose en acusaciones falsas o forzando a los detenidos a admitir su culpabilidad, etc.

¿Cómo se resolverá el problema de la disidencia?, ¿serán liberados todos los detenidos por problemas políticos, tal como ya se hizo entrever al liberar al primer contingente de 40 presos de los más connotados críticos y anunciando que en el futuro serán puestos en libertad los demás? Nada indica que se repetirá el XX Congreso del PCUS con una denuncia pública del más alto nivel de "las violaciones de la legalidad socialista" y que se abren cauces para la rehabilitación de las víctimas porque esto podría desatar una caja de Pandora que en nada ayudaría a progresar el actual programa de reestructuración. De todos modos queda pendiente ver los límites de la crítica y de la tolerancia del régimen de ella. El autor no plantea esas cuestiones relativas al desenvolvimiento de las críticas y de los conflictos que se generarán en el futuro inmediato.

Me siento obligado por el deber de hacer la reseña del libro a señalar ciertos errores y omisiones suyas más allá de las interpretaciones o enfoques personales. Concretamente, no es exacto que Jruschev había anunciado en 1956 su programa de sobrepasar al nivel económico de los Estados Unidos en el año de 1980 sino lo hizo en 1961 en ocasión del XXII congreso del PCUS. Por consiguiente, todos los argumentos en justificación del programa de Jruschov son, por lo menos, anacrónicos.

Igualmente, hay que reconocer que calificar el modelo del socialismo yugoslavo de anarquista pertenece al viejo arsenal propagandístico de principos de los años cincuentas. Aparte de la excomunión de la Yugoeslavia de Tito de la "comunidad socia- 
lista" por parte del Kominform en 1948 y de acusaciones abominables contra la dirección yugoeslava, nadie en el mundo ha creido que el sistema oroginal autogestionario puesto en marcha en aquellos años para sobrevivir el cerco del bloque soviético podía subsistir. En aquellos años podía sostenerse la sospecha, o si se quiere la acusación, anarquista. Pero no hay que olvidar que fue en 1955 cuando la nueva directiva soviética con Jruschov a la cabeza hizo una visita oficial a Yugoeslavia y por boca del secretario general del partido reconoció la vía yugoeslava al socialismo con su particular base autogestionaria, admitiendo, al mismo tiempo que la campaña contra Yugoeslavia fue "la provocación más monumental [...] de la historia del movimiento obrero revo-' lucionario internacional".

También me parece como una omisión grave no señalar la caída de Jruschev en 1964 por la alta burocracia del partido amenazada en su estabilidad y privilegios a causa del afán reformador del controvertido dirigente soviético. Creo que así se comprendería mejor por qué los antecedentes de las reformas de 1957 y 1962-64 habían fracasado, tal como lo observa con razón el autor, así como por qué el actual programa de reformas se distingue de los esbozos anteriores. No es casual $-\mathrm{y}$ así lo ve también $\mathrm{E}$. Montes- que la reestructuración económica en curso está acompañada por los cambios políticos en el sentido de tratar de democratizar el sistema de ejercicio del poder a fin "de que las grandes. masas del pueblo participen y jueguen un papel decisivo." (p. 64) Ese componente político faltó en los años de Jruschev y por ello su eliminación de la dirección fue relativamente fácil. El caso de Jruschev debió haber servido de ejemplo muy ilustrativo para el presente secretario general en su construcción de la renovación del sistema.

Me resulta particularmente difícil calificar el carácter del libro. El autor lo presenta como un "reportaje", tal vez para darle una forma más amplia y más directa. A mí no me convence del todo tal denominación porque siento que falta la observación directa, las vivencias propias y percepciones personales. Pero, puedo admitir que el autor hace suyas las observaciones de sus interlocutores en seleccionarlos y reproducir sus argumentos. No obstante, del libro no brota la espontaneidad del reportaje, lo caliente de la vida sino que se denota un gran esfuerzo de explicar el por qué y cómo de estos cambios, haciendo citas y referencias al pié de página. Con ello, el texto adquiere el carácter más expolicativo tal como se espera de un trabajo científico. Pero en tal caso se debería padir al autor que fuese más profundo, mejor docu- 
mentado y más analítico en cada uno de los enunciados. Ciertas partes, por ejemplo el análisis del mecanismo económico tradicional soviético, deberían ser objeto de un estudio más pormenorizado, detallado con base bibliográfica más amplia de la que maneja el autor.

En conclusión, soy de opinión de que el libro ganaría mucho más en su valor documental si el autor hubiera adoptado el estilo más sobrio, evitando una que otra grandilocuencia y ciertos giros retóricos ya desgastados por el tiempo, los que definitivamente no corresponden con el viento que sopla en la URSS bajo Gorbachov. Ello se hace evidente en contraste con la segunda parte del libro, en la cual se incluyen tres entrevistas con partidarios de las reformas radicales del sistema como lo son: B. Vladimirov, director de la revista especializada Ekonomicheskaya Gazeta, uno de los foros de debates sobre las cuestiones de la reforma económica; $\mathrm{N}$. Shislin, el jefe adjunto del departamento de propaganda en el comité central del partido, y T. Zaslavskaya, economista y socióloga del prestigiado instituto científico en Novosibirsk, sede de una filial de la Academia de Ciencias conocida desde muchos años por sus aportaciones científicas en diferentes ramas del conocimiento. También está incluído el texto de Zaslavskaya, "El mecanismo social del desarrollo de la economía" como apéndice, aunque el lector de Nexos pudo leerlo en octubre de 1985 con la presentación de F. Claudín. Por cierto, Montes interrogó a la autora del texto acerca de su supuesto carácter disidente que nunca lo tuvo ni en sus intenciones ni en su impacto. Zaslavskaya explicó que en realidad se trató de una versión suscinta de un estudio mucho más amplio y por esta forma condensada adquirió el temple más crítico para provocar discusión entre los 60 científicos invitados a la reunión. Estos documentos, por sí solos, revelan que las cosas en la URSS están cambiando, ya que el lenguaje adoptado es directo, franco y crítico, en comparación con el "lenguaje-madera" utilizado en los textos de los funcionarios y aún de los cierntíficosw sociales hace pocos años atrás.

A pesar de estas reservas y críticas, el texto amerita la lectura por todos aquellos quienes están interesados en lo que está sucediendo èn la URSS, país que se ha convertido - como lo observó N. Bobbio- "en otra gran potencia de la que depende, para bien o para mal, nuestro destino de pigmeos en tierra de gigantes".

JAN PATULA 